\title{
Online survey
}

Q1. From your experience, which one from the list below is the main obstacle for a coherent and effective CFSP/CSDP?

\begin{tabular}{lrr}
\hline & Percentage & $\mathrm{N}$ \\
\hline Lack of a common identity & 25 & 7 \\
Divergence among member state interests & 53.6 & 15 \\
Inappropriate institutions & 17.9 & 5 \\
\hline
\end{tabular}

Q2. Do you think that coherence and effectiveness of CFSP/CSDP have increased or decreased since 1991?

\begin{tabular}{lrr}
\hline & Percentage & $\mathrm{N}$ \\
\hline Increased & 92.9 & 26 \\
Decreased & 0 & 0 \\
Remained constant & 3.6 & 1 \\
\hline
\end{tabular}

Q3. Please can you indicate which of the following institutional reforms has increased coherence and effectiveness of CFSP/CSDP.

\begin{tabular}{lrr}
\hline & Percentage & $\mathrm{N}$ \\
\hline High Representative & 60.7 & 17 \\
Rotating Presidency & 7.1 & 2 \\
Policy Unit & 57.1 & 16 \\
Political and Security Committee & 60.7 & 17 \\
Constructive abstention & 7.1 & 2 \\
Common strategies & 21.4 & 6 \\
QMV for joint actions & 10.7 & 3 \\
Right of initiative for Commission & 32.1 & 9 \\
\hline
\end{tabular}


Q4. Do you consult with other national delegations prior to formal meetings?

\begin{tabular}{lrr}
\hline & Percentage & $\mathrm{N}$ \\
\hline Yes, always & 17.9 & 5 \\
Yes, most of the time & 71.4 & 20 \\
Yes, rarely & 10.7 & 3 \\
Never & 0 & 0 \\
\hline
\end{tabular}

Q5. If yes, how often does your delegation consult with other delegations prior to the formal meetings?

\begin{tabular}{lrr}
\hline & Percentage & $\mathrm{N}$ \\
\hline Many times per week & 53.6 & 15 \\
Once per week & 32.1 & 9 \\
Once per month & 10.7 & 3 \\
Less than once per month & 3.6 & 1 \\
\hline
\end{tabular}

Q6. From the following criteria, could you indicate which one you take into account in order to privilege communication with partners from other member states? $(1=$ to a lesser extent; $4=$ to a greater extent $)$

\begin{tabular}{lc}
\hline & Mean \\
\hline Geographical proximity (neighbourhood) & 2.7 \\
Size of the country & 2.5 \\
Economic interests & 2.4 \\
Security interests & 2.8 \\
Similarity of values and norms & 3.3 \\
\hline
\end{tabular}

Q7. From your own experience, which of the following images is closer to the predominant behaviour in CFSP negotiations?

\begin{tabular}{lrr}
\hline & Percentage & $\mathrm{N}$ \\
\hline Consensus-building & 96.4 & 27 \\
Hard-bargaining & 3.6 & 1 \\
\hline
\end{tabular}

Q9. According to your own experience, are there any sensitive issues that are excluded from discussions?

\begin{tabular}{lrr}
\hline & Percentage & N \\
\hline Yes & 46.4 & 13 \\
No & 50.0 & 14 \\
\hline
\end{tabular}


Q10. Which objective should be given priority in EU external action? $(1=$ to a lesser extent; 3 = to a greater extent)

Mean

Promotion of EU security interests $\quad 2.8$

Respect of human rights, democracy and rule of law $\quad 2.7$

Promotion of EU economic interests 2.4 